\title{
Peran Koperasi Wanita Terhadap Keberdayaan Perempuan Di Koperasi Wanita “Bunda Pertiwi” Desa Kraton Yosowilangun Kabupaten Lumajang
}

\author{
Anang Rakhmad, AT. Hendrawijaya, Deditiani Tri Indrianti \\ Program Study Pendidikan Luar Sekolah, Jurusan Ilmu Pendidikan, Fakultas Keguruan dan Ilmu \\ Pendidikan Universitas Jember. Jl. Kalimantan No. 37, TegalBoto, Jember 62811, Indonesia \\ Email : Anangrakhmad0705@gmail.com, Hendrawijayapls.fkip@unej.ac.id, \\ Indriantipkp@unej.ac.id.
}

\begin{abstract}
Abstrak
Seiring dengan perkembangan dan tuntutan akan kemajuan koperasi wanita dalam meningkatkan kesejahteraan dan meningkatkan kualitas sumber daya anggotanya, Maka sesuai dengan peran koperasi wanita yaitu meninggkatkan kesejahteraan serta meningkatkan kualitas SDM.Tujuan penelitian ini untuk mengetahui peran koperasi wanita terhadap keberdayaan perempuan di koperasi Wanita Bunda Pertiwi desa Kraton Yosowilangun Lumajang. Jenis penelitian yang digunakan adalah korelasional dengan menggunakan pendekatan kuantitatif Tempat penelitian ini di Koperasi Bunda Pertiwi di Desa Kraton Yosowilanggun Kabupaten Lumajang. penentuan responden menggunakan metode Populasi. Data penelitian terdiri atas data primer dan sekunder. Data primer dari penelitian ini diperoleh dari perhitungan hasil dari pengisian angket oleh responden yaitu anggota koperasi Bunda Pertiwi dan data data skunder diperoleh dari Dokumentasi dan studi pustaka. Hasil penelitian ini menunjukkan adanya peran koperasi wanita terhadap keberdayaan perempuan di koperasi wanita Bunda Pertiwi.
\end{abstract}

Kata kunci: Peran Koperasi Wanita, Keberdayaan Perempuan.

\section{The Role of Women's Cooperation Towards Women's Empowerment in the "Bunda Pertiwi" Women's Cooperation in Kraton Yosowilangun Village Lumajang Regency}

\begin{abstract}
Along with the development and demands for the advancement of women's cooperatives in improving welfare and improving the quality of its members' resources, it is in line with the role of women's cooperatives, namely increasing prosperity and improving the quality of human resources. Yosowilangun Palace Lumajang Palace. The type of research used is correlational using a quantitative approach. The place of this study is at the Bunda Pertiwi Cooperative in Yosowilanggun Kraton Village, Lumajang Regency. Determination of respondents using the Population method. The research data consists of primary and secondary data. Primary data from this study were obtained from the calculation of the results of filling out the questionnaire by respondents namely members of the Bunda Pertiwi cooperative and secondary data data obtained from the documentation and literature study. The results of this study indicate the role of women's cooperatives on women's empowerment in the Bunda Pertiwi women's cooperative.
\end{abstract}

Keywords: The Role of Women's Cooperatives, Women's Empowerment. 


\section{Learning Community: Jurnal Pendidikan Luar Sekolah, 3 (2), September 2019 - 24 Anang Rakhmad}

\section{PENDAHULUAN}

Koperasi merupakan suatu badan usaha yang dipilih oleh sebagian masyarakat dalam rangka meningkatkan taraf hidupnya. Selain koperasi, terdapat badan usaha lainnya yang memiliki sifat dan ciri yang berbeda dengan koperasi. salah satu ciri yang membedakan koperasi adalah dasar falsafahnya. Dasar falsafah koperasi untuk mencapai kesejahteraan bersama berdasarkan asas kekeluargaan sedangkan dasar falsafah badan usaha bukan koperasi untuk mencapai laba sebesar - besarnya. Menurut Undang-Undang Republik Indonesia No. 17 Tahun 2012 tentang Perkoperasian pasal 2 : "Koperasi didirikan dengan tujuan utamanya untuk mensejahterakan rakyat Indonesia serta ikut membangun tatanan ekonomi nasional", peran koperasi di Indonesia sangat dibutuhkan, karena koperasi memiliki karakteristik yang hampir sama dengan kondisi masyarakat Indonesia yang bersahaja, adanya koperasi di tengah masyarakat akan memberikan dampak positif bagi pertumbuhan ekonomi, karena dengan adanya unit-unit usaha yang dijalankan oleh koperasi otomatis roda perekonomian pun akan menggeliat, sehingga pada masa pembangunan ini koperasi sangat besar sekali peranannya dalam sektor kehidupan perekonomian bangsa Indonesia.

\section{METODE}

Penelitian ini dilaksanakan dalam kurun waktu 6 Bulan Dengan perincian waktu penelitian 1 Bulan persiapan 2 Bulan penggalian data 3 Bulan pengerjaan laporan. Jenis penelitian yang digunakan adalah korelasional dengan menggunakan pendekatan kuantitatif Penentuan tempat penelitian menggunakan teknik purposive area yaitu bertempat di Koperasi Wanita Bunda Pertiwi. Teknik penentuan informan menggunakan teknik populasi. Dimana tujuan penelitian ini memperoleh data yang nantinya bisa mendeskripsikan peran koperasi wanita terhadap keberdayaan perempuan. responden utama pada penelitian ini adalah Anggota Koperasi Wanita dan responden pendukung pengelola serta pengurus koperasi wanita. Data penelitian terdiri atas data primer dan sekunder. Data primer adalah data yang diperoleh secara langsung dari subjek penelitian. Data primer pada penelitian ini diperoleh dari anggota koperasi wanita "Bunda Pertiwi " dengan menggunakan instrumen pengambilan data dan Data sekunder adalah data yang diperoleh secara tidak langsung dari dokumen atau sumber data lainnya. Data sekunder dalam penelitian ini berupa dokumentasi atau sumber informasi (kepustakaan) yang terkait.

\section{HASIL DAN PEMBAHASAN}

Berdasarkan data yang diperoleh ketika saat penggalian dan pengumpulan data dilapangan, dapat dirumuskan temuan / hasil penelitian yang sesuai dengan rumusan masalah pada penelitian guna menjawab bagaimana Peran koperasi wanita terhadap keberdayaan perempuan di koperasi wanita "Bunda Pertiwi" desa kraton Yosowilangun kabupaten Lumajang sesuai data yang didapatkan ketika penelitian dilapangan bahwa adanya peran koperasi wanita terhadap keberdayaan perempuan Sesuai dengan rumusan masalah yaitu bagaimana peran koperasi wanita terhadap keberdayaan perempuan di koperasi wanita bunda pertiwi desa kraton kecamatan yosowilangun kabupaten lumajang. Berdasarkan hasil penelitian yang telah dilakukan, maka dapat diketahui bahwa Peran koperasi wanita terhadap keberdayaan perempuan di koperasi wanita bunda pertiwi desa Kraton Yosowilangun Lumajang. Hal tersebut diperoleh dari hasil analisis data regresi linier sederhana yang diolah menggunakan alat bantu SPSS (Statistical Package of the Social) seri 24.0. dengan demikian dapat disimpulkan. Hipotesis Nihil (Ho) ditolak dan Hipotesis Alternatif (Ha) diterima yaitu adanya peran Koperasi Wanita terhadap Keberdayaan Koperasi Wanita "Bunda Pertiwi", Desa Kraton, Kecamatan Yosowilangun, Kabupaten Lumajang Peran koperasi yang dimaksud adalah berkaitan dengan usaha meningkatkan pendapatan para anggotanya (Pandji Anoraga, 1997:163). Yang dimaksud disini adalah apakah ada peningkatan kesejahteraan serta dapat meningkatkan kualitas SDM setelah menjadi anggota koperasi dari pada sebelum menjadi anggota, apakah tidak ada perubahan, atau bahkan terjadi penurunan kesejahteraan dari sebelum menjadi anggota koperasi. Hal ini 


\section{Learning Community: Jurnal Pendidikan Luar Sekolah, 3 (2), September 2019 - 25 Anang Rakhmad}

menunjukkan bahwa peran koperasi wanita sangat penting dalam berlangsungnya proses pemberdayaan perempuan karena dapat mempengaruhi tinggi rendahnya proses pemberdayaan. Sedangkan untuk analisis dari setiap indikator adalah : untuk indikator meningkatkan kesejahteraan dengan keberdayaan perempuan Menurut Badrudin (2012:154) Dalam paradigma pembangunan ekonomi, perubahan kesejahteraan masyarakat merupakan bagian yang tidak terpisahkan. Hal ini dikarenakan pembangunan ekonomi dikatakan berhasil jika tingkat kesejahteraan masyarakat semakin baik. Keberhasilan pembangunan ekonomi tanpa menyertakan peningkatan kesejahteraan masyarakat akan mengakibatkan kesenjangan dan ketimpangan dalam kehidupan masyarakat. Hal ini menunjukkan bahwa meningkatkan kesejahteraan mempengaruhi proses keberdayaan perempuan. Hasil temuan ini membuktikan bahwa meningkatkan kesejahteraan dapat mempengaruhi pemberdayaan perempuan yang memberikan dampak langsung terhadap proses peningkatan kesejahteraan anggota koperasi wanita.

Untuk indikator meningkatkan kualitas SDM dengan keberdayaan perempuan Mathis dan Jackson (2006:3) Sumber Daya Manusia adalah rancangan sistem-sistem formal dalam sebuah organisasi untuk memastikan penggunaan bakat manusia secara efektif dan efisien guna mencapai tujuan organisasi. Demikian pula menurut The Chartered Institute of Personnel and Development (CIPD) dalam Mullins (2005). Sumber daya manusia dinyatakan sebagai strategi perancangan, pelaksanaan dan pemeliharaan untuk mengelola manusia untuk kinerja usaha yang optimal termasuk kebijakan pengembangan dan proses untuk mendukung strategi. Hal ini menunjukkan bahwa meningkatkan kualitas SDM dapat mempengaruhi proses keberdayaan perempuan. Hasil temuan ini membuktikan bahwa meningkatkan kualitas SDM sangat berperan penting terhadap proses keberdayaan perempuan.

\section{SIMPULAN}

Kesimpulan dari penelitian ini yaitu ada peran koperasi wanita terhadap keberdayaan perempuan di koperasi wanita bunda pertiwi desa Kraton Yosowilangun Lumajang, dengan kategori tingkat peran yang sangat tinggi. Saran dari penelitian ini yaitu . Bagi Koperasi Wanita Bunda Pertiwi perlu melakukan peningkatan programprogram anggota yang lebih memberikan manfaat secara bersama sehingga mampu meningkatkan kesejahteraan para anggota Koperasi Wanita Bunda Pertiwi. dan Bagi Penelitian Selanjutnya. Diharapkan dapat melakukan penelitian lebih lanjut terkait dengan peran Koperasi Wanita terhadap Keberdayaan Koperasi Wanita

\section{DAFTAR PUSTAKA}

Badrudin, Rudy. 2012. Ekonomika ekonomi daerah. Edisi Pertama. Yogyakarta: UPP STIM YKPN.

Anoraga, Pandji, 2010, Manajemen Bisnis, Edisi Kedua, Rineka Cipta, Jakarta.

Mathis dan Jackson. 2006. Human Resource Management, alih bahasa. Jakarta: Salemba Empat. 